\title{
La política exterior en tiempos de progresismo
}

Recibido: 10/12/2017

Aprobado: 12/04/2018

\author{
RUT DIAMINT \\ Universidad Torcuato Di Tella \\ rutd@utdt.edu
}

\begin{abstract}
RESUMEN
Doce años después del resurgimiento de la izquierda en América Latina, presenciamos su ocaso y la emergencia de la derecha. En el presente artículo, la autora se pregunta si esta situación responde a una crisis coyuntural de los gobiernos progresistas de América Latina o en realidad se trata del fracaso de esos proyectos alternativos que solo produjeron cambios cosméticos. Analiza el fracaso de los intentos por crear nuevas reglas de juego en el sistema internacional, en la política nacional y en la construcción regional por parte de los gobiernos progresistas, debido a la utilización de medios anticuados — basados en esquemas y conceptos de los tiempos de la Guerra Fría - en un contexto global diferente. El artículo inicia con una exposición sobre las visiones generales de las propuestas progresistas, para posteriormente analizar los casos de Brasil y Venezuela, y finalizar con las conclusiones sobre el supuesto del trabajo.
\end{abstract}

Palabras clave: Crisis de los gobiernos progresistas, sistema internacional, Brasil, Venezuela.

\section{Foreign policy in times of progressivism}

\begin{abstract}
Twelve years after the resurgence of the left in Latin America, we are now witnessing its dawn and the emergence of the right. In the present article, the author asks if this situation responds to a situational crisis of the progressive governments of Latin America or, if in reality, we are witnessing the failure of these alternative projects that only produced cosmetic changes. The author analyzes the failed attempt to create new rules in the international system, national politics and the regional construction by the progressive governments, because of the use of outdated means - based on schemes and concepts of the Cold War- in a different global context. The article begins with a general exposition of the progressive proposals to later analyze the cases of Brazil and Venezuela, ending with conclusions of the main hypothesis.
\end{abstract}

Keywords: Crisis of the progressive governments, international system, Brazil, Venezuela 


\section{Introducción}

E n el 2008, Cristina Fernández criticó a los Estados Unidos por arrastrar en su crisis financiera a los países latinoamericanos. En el 2009, Hugo Chávez enfrentó a Colombia informando sobre una supuesta guerra, mientras que Uribe lo denunciaba ante el Consejo de Seguridad de las Naciones Unidas y ante la Organización de Estados Americanos (OEA). En el 2009, Rafael Correa exponía que la Unión de Naciones Suramericanas (UNASUR) realizó en pocos años lo que a la Unión Europea le llevó varias décadas. Estos tres casos muestran una inserción diferente de las naciones sudamericanas en el escenario global. La región mostraba protagonismo. ${ }^{1}$ Ese alto perfil coincidía con un nuevo posicionamiento nacional de los gobiernos. Se daba cuenta del resurgimiento de la izquierda en América Latina (Levitsky y Roberts, 2011; Arditi, 2009; Panizza, 2009; Castañeda y Morales, 2008). Doce años después, estos intentos decayeron. Vale preguntarse si responde a una crisis coyuntural de los gobiernos progresistas de América Latina o en realidad se trata del fracaso de esos proyectos alternativos que solo produjeron cambios cosméticos.

El ascenso, por medio de elecciones democráticas, de gobiernos populares y con tendencias de izquierda generó expectativas positivas, especialmente para revertir la profunda desigualdad social imperante. Todos ellos reformaron instituciones o constituciones, y desplegaron estrategias para permanecer en el poder. Como en un dominó, van cayendo esas ilusiones y resurgen tendencias de centro derecha. ¿A que atribuir ese súbito ocaso?

La nueva izquierda latinoamericana surgió en un contexto peculiar signado por la desaparición de la Unión Soviética y su supuesta influencia en los movimientos socialistas en la región. Asomó en un momento en que la democracia, que prometía bienestar y trabajo, entró en crisis. Se instaló en medio de un cambio del juego de la política que se tornó más mediática y menos militante. Se estableció cuando los países se transformaban en urbanos, recargando las demandas en las ciudades. Nació como una revolución desde arriba, sin derribar un Gobierno y sin modificar el modo de producción. Surgió por la reacción ciudadana a una clase política denostada por su ineficiencia y los altos grados de corrupción.

\footnotetext{
$1 \quad$ El término exacto sería "actorness", que no tiene una traducción literal. Refiere a una identificación interna y un reconocimiento externo de la capacidad de actuar e influir de un determinado actor.
} 
Los casos difieren mucho entre sí. Tanto Rafael Correa en Ecuador como Evo Morales en Bolivia aplicaron políticas populistas mientras desarrollaban un crecimiento económico sostenido, una mayor distribución de la riqueza y la ampliación de mercados. Sus gobiernos construyeron futuro, aunque, tal como explica Lozano (2005, p. 134), lo hicieran desde una izquierda populista que "cuando alcanza el poder o participa del mismo sostiene una política clientelista en su vínculo con las masas".

En este escrito se considera que hubo un fracaso de estos gobiernos al intentar crear nuevas reglas de juego en el sistema internacional, en la política nacional y en la construcción regional, utilizando medios anticuados para un contexto global diferente. Este argumento se enfoca en las políticas exteriores, aunque por momentos sea necesario recurrir a cuestiones de orden doméstico. En primer lugar, se expondrá sobre las visiones generales de las propuestas progresistas. En segundo término, se analizarán dos casos: Venezuela y Brasil. Finalmente, en las conclusiones se retoma el supuesto del trabajo.

La hipótesis que guía este escrito es que los gobiernos progresistas de América Latina construyeron una política de poder basándose en esquemas y conceptos de los tiempos de la Guerra Fría. Descontando otros elementos que complicaron el modelo, sus propuestas no crearon bienestar estable. La sociedad entonces eligió otra vía de prosperidad. Aunque aún es temprano para afirmarlo, la derecha "moderna" que siguió a esos gobiernos progresistas parece haber entendido la demanda por una nueva política que los gobiernos de izquierda no supieron procurar.

\section{Un pensamiento fosilizado}

Los medios periodísticos de las grandes potencias bautizaron como "marea rosa" a las nuevas tendencias de izquierda de América Latina que se inician con la asunción de Hugo Chávez a la presidencia de Venezuela en 1999. ${ }^{2}$ Los orígenes del término se atribuyen a Larry Rohter (2005), periodista del New

2 Argentina: Néstor Kirchner (2003-2007), Cristina Fernández de Kirchner (2007-2015); Bolivia: Evo Morales (2006-presente); Brasil: Luiz Inácio Lula da Silva (2003-2011), Dilma Rousseff (2011-2016); Chile: Ricardo Lagos (2000-2006), Michelle Bachelet (2006-2010, 2014-presente); Ecuador: Rafael Correa (2007-2017), Lenin Moreno (2017-presente); El Salvador: Mauricio Funes (2009-2014); Honduras: Manuel Zelaya (2006-2009); Nicaragua: Daniel Ortega (1979-1990, 2007-presente); Paraguay: Fernando Lugo (2008-2012); Perú: Ollanta Humala (2011-2016); Uruguay: Tabaré Vázquez (2005-2010, 2015-presente), José Mujica (2010-2015); Venezuela: Hugo Chávez (1999-2013), Nicolás Maduro (2013-presente). 
York Times, quien caracterizó la elección de Tabaré Vázquez, de Uruguay, diciendo: "No es tanto una marea roja, como una rosa".

Laura Carlsen (2006), periodista e investigadora asociada al Center for International Policy, haciendo eco de los intentos de caracterizar a esos movimientos latinoamericanos, se preguntaba: ¿Qué se considera "izquierda"? ¿Cuánto margen de maniobra tienen los autoproclamados gobiernos izquierdistas para hacer cambios en un mundo globalizado? ¿Y qué significan estos cambios a nivel regional?

Este giro en varios países latinoamericanos era una consecuencia lógica después de las reformas neoliberales que dejaron el saldo de una mayor deuda externa y un notable aumento de la pobreza. Ludolfo Paramio (2003) argumentaba que las victorias de la izquierda se explican por "el contexto de decepción social que se ha ido extendiendo por América Latina a partir de 1998 con el deterioro del crecimiento económico que, tras las reformas estructurales, culminó en 1997'. Estados inestables en los cuales las relaciones laborales se deterioraron y las tasas de desempleo urbano alcanzaron un máximo histórico no daban cobertura al desamparo y la falta de asistencia social. Con altos niveles de desigualdad social y una expandida desconfianza en los políticos, el cambio de orientación era una demanda perceptible que algunos líderes supieron capitalizar.

No obstante, las propuestas de los gobiernos progresistas fueron antiguas, conservadoras y regresivas. Se retornó a la teoría de la dependencia, se volvió a los conceptos de deterioro de los términos de intercambio. Se ensalzó la lucha armada setentista. Se palió el desamparo con bonos populistas que no redundaron en trabajo estable remunerado. Ese regreso se realizó con otros condicionantes que también retrotraen al pasado. Primero, la disponibilidad de enormes rentas provenientes de materias primas otorgaba recursos ignorados a los gobiernos para seducir con sus políticas de bienestar social. En el largo plazo, ello demostró que esa economía era contraria a la creación de riqueza a través de la productividad, la eficiencia y la competitividad (Weyland, 2009, p. 151). Además, como enunciaban los sectores más radicalizados de esos mismos movimientos, crearon un sistema económico dependiente de los recursos extractivos, que, a su vez, eran dependientes de los mercados globales.

Segundo, a mediados del siglo pasado no existía un proceso de globalización como en el presente. La capacidad de influir sobre mercados estaba muy limitada y las potencias concentraban más poder que en la década de 1970. 
Algunos sostienen que, pese a sus intenciones, era imposible luchar contra el poder del capitalismo global (López Segrera, 2016). Otros demuestran que las economías estatizadas en América Latina fracasaron por sus propios errores (Escobar, 2010; López Maya y Lander, 2010; López Maya, 2007).

Tercero, durante la década de 1980, los militares perdieron su capacidad de constituirse como un factor de poder decisivo para controlar la política. Pese a las variaciones en el grado y la calidad del control civil democrático de las Fuerzas Armadas entre los países de la región, los militares perdieron la capacidad de imponerse por medio de un cambio de régimen político. No obstante, seguían siendo actores con poder y autonomía dispuestos a participar en la toma de decisión.

Cuarto, el retorno populista, condimentado con una retórica que acusaba de todos los males a las administraciones anteriores y que se atribuía la verdadera y única representación del pueblo, sedujo por un tiempo, pero luego descubrió una nueva moral, poco revolucionaria. Así, la corrupción, prácticas autoritarias, control de los medios de comunicación, represión de opositores, todo ello sin una ética de cambio trajo desilusión, divisionismo y pérdida de legitimidad.

Por cierto, hubo innovaciones respecto del modelo del pasado, especialmente en lo referido al activismo de las organizaciones de la sociedad civil, fenómeno que surge con las transiciones a la democracia. Los movimientos sociales ganan protagonismo en estos gobiernos de izquierda, con demandas no partidarias vinculadas con la pobreza y la inserción laboral, aunque también toman fuerza los grupos indígenas, colectivos de orientación sexual, campesinos, jóvenes, mujeres, junto con los más tradicionales que reclamaban por los derechos humanos y la democracia. En algunos casos, como por ejemplo en Bolivia, ese activismo les dio acceso a puestos de decisión política. En otros casos, como en Argentina, fueron utilizados por el Gobierno para ampliar la base de movilización política.

Maristella Svampa (2017, p. 51) comentaba que la denominación de progresismo fue acuñada por varios mandatarios:

[...] se impuso como lugar común la denominación genérica de progresismo; si bien tiene el defecto de ser demasiado amplia, esta categoría permite abarcar una diversidad de corrientes ideológicas y experiencias políticas gubernamentales, desde aquellas de inspiración más institucionalista hasta las más radicales, vinculadas a procesos constituyentes. 
El debate académico no terminaba de consensuar el significado de estas tendencias que utilizando una retórica neosetentista se adaptaban a las reglas de mercado capitalista. Jorge Castañeda (2006) hablaba de las dos izquierdas. Una de ellas era sensata y la otra demagógica, según la herencia institucional, sus movimientos sociales y la trayectoria de los partidos progresistas. Benjamín Arditi (2009, p. 233) también exponía sus dudas respecto a la clasificación de esta nueva izquierda:

Es cada vez más difícil entender lo que denota el término desde que el grueso de los partidos socialistas y las organizaciones de centroizquierda comenzó a dejar de lado sus resistencias a la economía de mercado y a desechar paulatinamente el lenguaje de la lucha de clases, la liberación nacional, el internacionalismo, la soberanía westfaliana estricta y demás.

La marea rosa se beneficiaba de los errores de los gobiernos neoliberales y la crisis de representación del sistema de partidos liberal. Al mismo tiempo que se convocaba a sectores excluidos, se recuperaba la militancia juvenil y se hacían eco de los nuevos derechos humanos, tanto los consagrados en los "objetivos del milenio" de las Naciones Unidas, como la novel legitimidad de grupos novedosos como los LGTBI. Todo ello, sin embargo, condimentado por viejas prácticas clientelares (Weyland, 2013). No se impulsaban organizaciones autónomas sino una dominación personalista y el endiosamiento de liderazgos individuales.

Tampoco se buscó la reconstrucción del sistema de partidos, haciendo hincapié en la inclusión de esos nuevos actores sociales. Al contrario, el liderazgo individual atomizaba las iniciativas institucionales y la autonomía de los grupos sociales (Lozano, 2015, p. 145; Goldfrank, 2007, pp. 55-58). La convocatoria era a través del discurso, que reforzaba la identidad del "pueblo" y el líder. Una retórica anómala que no conducía a la reconfiguración institucional de identidades políticas.

Por otra parte, el socialismo propagado por varios de estos dirigentes era como mucho un:

[...] capitalismo más equilibrado y por lo tanto más reglamentado, pero un capitalismo que de todos modos mantiene la impronta de muchos de los cambios estructurales ejecutados en las dos décadas anteriores por las severas recomendaciones de reformas macroeconómicas y sociales en clave neoliberal (Vilas, 2005, p. 88). 
Francisco Cantamuttoi $(2013$, p. 9) detalla que los gobiernos de la nueva izquierda aceptaban el mercado como institución básica de asignación de bienes y recursos, y agregaba: "Sin embargo, repetimos, no encontramos cambios sustantivos en lo económico que permitan diferenciar a estos gobiernos de otros ideológicamente distantes".

Incluso, la reforma agraria, bandera irreductible de las izquierdas del siglo XX, no avanzó más allá de confiscar algunas tierras desocupadas, mientras que el retorno desde las poblaciones urbanas marginales al campo no contó con los estímulos necesarios para convertirlo en una propuesta atractiva. Se apoyó la creación de cooperativas, a las que se dio créditos en mejores condiciones que las de la banca, pero no fueron suficientes las políticas para insertarlas en los mercados.

En suma, cambios tibios o precipitados y sin fundamentación, retórica personalista y un modelo de socialismo sin modificar el mercado no fueron herramientas suficientes como para afianzar estos modelos en las sociedades latinoamericanas. A ello se agrega los notorios índices de corrupción que minaron la credibilidad de estos proyectos alternativos. "Esta realidad económica es la principal causa de las recientes derrotas. Pero no es la única. Muchos líderes latinoamericanos de izquierda fueron víctimas de la corrupción endémica de la región, y subestimaron la creciente intolerancia hacia esos delitos" (Castañeda, 2016). El impeachment de Dilma Rousseff y las acusaciones a Lula da Silva; las evidencias de enriquecimiento ilícito de Cristina Fernández de Kirchner; el arresto del vicepresidente ecuatoriano Jorge Glas; el procesamiento en ausencia al expresidente Ricardo Martinelli de Panamá; las numerosas - y paralizadas - denuncias contra Daniel Ortega por corrupción, agravadas con el proyecto del canal financiado por China; "el nueragate" de la presidenta Michele Bachelet y otros miembros de la clase política chilena, acusados de hechos indebidos, contaminaron ese reformismo ligero. El rechazo al neoliberalismo y la crisis de los partidos políticos dieron lugar a pensar al Estado como una herramienta de transformación social (Thwaites Rey, 2009). El Estado ya no era el instrumento de una burguesía excluyente, sino que podía ser recuperado para promover el cambio político. Sin embargo, ello no significó mucho más que llenar las agencias de Gobierno con adictos al régimen, muchos de ellos sin preparación para administrar, que estaban más motivados por su beneficio individual que en sostener una revolución.

Todos estos casos no dan cuenta de una nueva forma de hacer política, sino de las peores prácticas que han sido habituales en la historia latinoameri- 
cana. No alcanzó con evocar mediante un discurso populista al pueblo frente a una élite depredadora y antinacionalista. La marea rosa fue tan depredadora como los gobiernos anteriores a los que supuestamente intentaban superar. En suma, y teniendo presente que hay diferencias importantes entre el proceso de Ecuador y Bolivia y el de Argentina y Venezuela, por señalar unos ejemplos, la marea rosa fue una esperanza truncada.

En los dos apartados siguientes se analiza con más detalle dos experiencias diferentes que han conducido al fracaso de esa esperanza.

\section{Brasil, quien mucho abarca}

Brasil ha sido siempre la promesa. Durante la administración de Luiz Inácio Lula da Silva, esa grandeza de futuro parecía hacerse realidad. Una serie de artículos recogían esa visión que auguraba una nueva potencia mundial (Amorim, 2010; Brainard y Martínez-Díaz. 2009; Hurrell, 2008; Gratius, 2007). El resto de los países de la región expresaban tibiamente una relativa desconfianza hacia la construcción de hegemonía brasileña. Brasil alternaba ante los vecinos en mostrar la grandeza de la nación y evitar mostrar pretensiones hegemónicas. No obstante, su desempeño regional era el de un hegemón benévolo bajo cuyo crecimiento se beneficiarían los demás países sudamericanos, estrategia recibida con suspicacia entre sus vecinos (Schenoni, 2014; Gamboa Valenzuela, 2011; Sorj y Fausto, 2011; Gomes Saraiva, 2010).

Junto con Rusia, India, China y luego Sudáfrica, imaginaban un BRICS que cambiarían las reglas del juego internacional. Una creciente presencia en el continente africano, también pronosticaba ese supuesto rol global (Muggah, 2015). Aunque, como bien señala Christina Stolte (2013), en ese acercamiento había intereses comerciales muy concretos: "Los principales actores de Brasil en África, como el gigante petrolero Petrobras o la compañía minera Vale, están profundamente involucrados en la extracción de los recursos de África”.

Brasil no buscaba desafiar especialmente a Estados Unidos, aunque en ocasiones concretas mostró que no aceptaría las presiones del país del norte. El Gobierno del Partido de los Trabajadores (PT) evitaba confrontaciones en las que tenía posibilidades de perder y se concentraba en extender su influencia en los espacios en los que existía menor afluencia de intereses. Como explican Gomes Saraiva y Valença (2011, p. 106): “[Para] las pretensiones 
brasileñas no solo era importante el liderazgo regional, sino también el aumento de influencia entre los países del sur". Era una política tradicional de convertirse en actor global, que había estado en las pretensiones de los políticos brasileños desde inicios del siglo XX.

La construcción de poder de Lula se sostenía en los viejos paradigmas del realismo, en tradicionales ideas soberanistas y en una lectura del sistema internacional unipolar. Lula aquietó a los oponentes mostrando una conducta fiscal impecable, incrementando las exportaciones y beneficiando a los pobres con planes sociales que a muchos les permitieron pasar de pobres a una inestable clase media. Dejó el Gobierno con cerca de un $80 \%$ de aprobación. Pero desde la oposición se destacaban sus falencias. Como explica Perry Anderson (2011): "Para Cardoso y sus seguidores, todavía dominantes entre la intelectualidad y en los medios, Lula personifica las tradiciones más regresivas del continente, su Gobierno es solo otra variante del populismo demagógico de un líder carismático, despectivo a la vez de la democracia y la cortesía, comprando el favor de las masas con caridad y adulación".

La estrategia de inserción internacional del Gobierno peteísta se basó en el modelo de la Escuela de Guerra. Sumado a ello, la histórica relación de Itamaraty, las élites políticas y las Fuerzas Armadas daba mayor vigencia al pensamiento de la Escuela. Persistía la creencia en la centralidad de los medios militares para dar poder a las naciones. Así, los conceptos de Amazonía Verde y Amazonía Azul, cargados de una visión geopolítica tradicional, fijaban los límites imperiales de un espacio geográfico que se constituía como una variable decisiva de las decisiones estatales. El poder se asentaba también en esta visión geopolítica que tomaba prestado los argumentos de Homer Dixon (1999) sobre las guerras del futuro por la escasez de recursos naturales y de Michael Klare (2008), la geopolítica de los recursos naturales y el control de rutas para acceder a ellos: "Las rutas marítimas y la infraestructura costera que las apoyan son la tabla de salvación de la economía global actual". La llamada geopolítica crítica daba sustento para redireccionar las misiones militares y justificar el aumento de recursos para las Fuerzas Armadas.

Sin embargo, la cuestión de los derechos humanos no fue parte de su agenda, ni en lo referente al pasado nacional, ni en sus vinculaciones con países como Sudán, Zimbabue o China. Tampoco fue un defensor de las organizaciones de la sociedad civil, ni prosperaron en su administración, en la medida esperada de un Gobierno progresista, las políticas de igualdad de género y 
raza. La noción soberanista e hiperpresidencialista confrontaba con las ONG, sindicatos y grupos sociales, mientras el crecimiento derramaba mejoras indudables en los sectores bajos.

Para el resto de los países de la región, negociar con Brasil era frustrante. No cedía el dominio absoluto de sus políticas. Parafraseando la conocida canción de Pablo Milanés: "A todo dices que sí, a nada digo que no", ${ }^{3}$ pero terminadas las reuniones, Brasil omitía reformas a pesar de haberlas acordado minutos antes. La autonomía del país era un principio esencial, aunque nunca comunicado expresamente.

Ese predominio no se asentaba en una superioridad militar. Por el contrario, Brasil puso mucho empeño en construir, en el marco de UNASUR, la Comisión de Defensa Sudamericana. Ello no debe entenderse como un intento neto de cooperación militar, sino que se vinculaba a dos intereses diferentes. Por una parte, frenar las ideas de Hugo Chávez para crear una OTAS, una alianza militar del Atlántico Sur. Por otra parte, cierta inquietud por las crecientes compras de equipamiento militar de varios países de la región. La cooperación buscaba asegurar un relativo control de las políticas de defensa $\mathrm{y}$, además, acordar con los miembros para que preferentemente compraran material militar a las industrias brasileñas.

No todos coincidían con los beneficios de las políticas del PT. Aécio Neves (2016), candidato presidencial opositor, consideraba que hubo mucha retórica global y pocos logros. Además, agregaba: "A pesar de la importancia obvia de las relaciones exteriores en nuestro país, hemos visto cómo la diplomacia brasileña ha perdido su brillo en el transcurso de los últimos años, quedando inexplicablemente relegada a una posición secundaria tanto en el debate público nacional como en el escenario internacional".

El derrumbe del gigante fue estrepitoso. No puede asignarse solamente a una reacción de las élites económicas tradicionales, que tuvieron su buena parte en destituir a Dilma Rousseff. Las élites económicas locales e internacionales jugaron en contra de la política popular del PT. Pero centralmente la crisis de Brasil derivó de un alto nivel de corrupción gubernamental junto con una ineptitud en la administración del Estado.

Rousseff se defendió, acusó y recusó a sus detractores. Dio innumerables conferencias de prensa. Pero no todo se centraba en la presidencia. Eduardo Cunha, presidente de la Cámara de Diputados, que autorizó el impeachment

3 Años, de Pablo Milanés. 
de Dilma en diciembre del 2015, cinco meses después fue removido de su puesto por la Corte Suprema por múltiples cargos de corrupción.

Otro aspecto de ese derrumbe reside en el personalismo de la política. Lula fue un presidente carismático, ingenioso, intrépido. Lograba cautivar a las masas y seducir a los empresarios. Algunos consideran que sus encantos no alcanzaron para gobernar bien (Diaz y Almeida, 2008, p. 21). Lula concentró poder en sí mismo. No fortaleció las instituciones ni afianzó el juego democrático. Lula no hacía reuniones de gabinete, sus vínculos con los ministros de su Gobierno eran de disciplina absoluta. Sus manejos con los parlamentarios que obligaron a la temprana renuncia de su estrecho colaborador y jefe de gabinete, José Dirceu, mostraron poco apego a la legalidad. En política exterior no pudo conciliar la dicotomía entre mantener estrictamente el principio de no intervención en los asuntos de otros Estados con la voluntad de convertirse en un actor global, que obliga a intervenir en cuestiones de otras naciones. La fortaleza de Brasil quedó estancada.

De estos señalamientos surgen preguntas: ¿Son proyectos personales y por eso fracasan sus seguidores? ¿Intentó Lula fortalecer la democracia? ¿Se subestimaron las reacciones de la oposición? Mirando otras experiencias latinoamericanas, estos líderes fuertes, usurpadores de poder institucional, logran dominar la escena política, pero solo temporalmente (Diamint y Tedesco, 2015). Y cuando caen, lo hacen estridentemente.

Ni Lula ni Rousseff cambiaron la cultura política de Brasil. Tampoco entendieron que se habían producido cambios en la sociedad y que los tres intentos anteriores de Lula de acceder a la presidencia se habían realizado en un contexto nacional e internacional muy diferente. Había una demanda por profundizar la democracia que no alcanzaba a cubrirse con la llamada Bolsa Familia. Y como sugiere Perry Anderson (2011): "Lula ni movilizó ni siquiera incorporó al electorado que lo aclamó. Ninguna nueva propuesta estructural nueva dio forma a la vida común. La identidad de su Gobierno fue, si acaso, la desmovilización". Tal vez algunos insinúen que Lula no pudo avanzar más por temor a la reacción de los tradicionales poderes fácticos. Aquí se conjetura que no hubo voluntad de cambio, que los gobiernos peteístas solo revindicaron viejas banderas, y reiteraron viejas prácticas que no lograban posicionar a Brasil en ese futuro siempre imaginado. 


\section{Las penurias de la Revolución bolivariana}

Hugo Chávez llegó al poder para instalar una democracia radical, de participación directa, incorporando a clases sociales históricamente excluidas. Ganó sus primeras elecciones con absoluta legitimidad. Puso en marcha programas sociales que le dieron incluso el apoyo de opositores. En el ejercicio del mando fue profundizando rasgos autoritarios, promovió una alta polarización de la sociedad y manipuló las instituciones estatales.

Durante su primer mandato, y asesorado por el argentino Norberto Ceresole, Chávez tomó varias iniciativas modeladas en los primeros gobiernos de Juan Perón (1946-1955). Atrasaba cincuenta y cinco años. No solo había cambiado rotundamente el contexto internacional, también era muy distinta la economía y la participación de la sociedad civil. El mayor logro de Ceresole fue supuestamente convencer a Chávez sobre la centralidad de la relación caudillo, Ejército y pueblo. Sus públicas expresiones antisemitas complicaban la campaña del presidente venezolano y por ello le solicitaron que abandonara el país (Clarín, 1999). Chávez (2014, p. 450) dijo que su desacuerdo con Ceresole se debió a que "empezó a decir que Chávez era una hechura suya... La vanidad... Eso nos alejó".

Chávez reescribió la Constitución, plebiscitó su reelección, empoderó a los militares, dominó la legislatura, y tuvo especial hostilidad contra los medios de comunicación. En política internacional fue un generoso donante de los países caribeños y latinoamericanos, mientras esgrimía una fuerte crítica antiestadounidense y anticapitalista. Se vinculó con países de dudosa formación democrática, que a su vez eran enemigos de Estados Unidos. Intentó, sin éxito, liderar América Latina y creó un organismo regional que subsistió como un mecanismo personal de exportación de su modelo. Sus alianzas con Irán, Siria, China, Rusia, Libia, Benín, Angola o Afganistán constituían un eje heterogéneo que solo se distinguía por su oposición a los Estados Unidos. La relación privilegiada con Cuba, como benefactor, socio comercial y promotor ideológico, cristalizó intercambios irregulares entre barriles y recursos humanos.

Rodrigo Salazar (2008, p. 222) sostiene: "Las diversas acciones de Chávez son consistentes con un objetivo que ha declarado en diversas ocasiones; a saber, la creación de polos de poder alternativos que reduzcan la hegemonía mundial de Estados Unidos". En el documento Lineas generales del plan de desarrollo económico y social de la nación 2007-2013 se pro- 
ponía: "Fortalecer los movimientos alternativos en Centroamérica y México en la búsqueda del desprendimiento del dominio imperial" (Salazar, 2008, p. 229). Si coincidimos con estas expresiones, se debe reconocer que Chávez no ha sido exitoso en su cometido. La sustitución del esquema tradicional de inserción internacional de Venezuela tuvo como órgano privilegiado la Alternativa Bolivariana para las Américas (ALBA) ${ }^{4}$ que demostró ser una extensión del poder personal de Chávez y que sucumbió con la muerte del presidente. Pese a que pregonaba la "consolidación del eje de liderazgo CubaVenezuela-Bolivia para impulsar el ALBA como alternativa al ALCA y a los TLC" (MPPP, 2007, p. 48), ni Bolivia ni Ecuador intentaron dinamizar el ALBA tras la muerte de Chávez. El ALBA no logró ser un polo hegemónico en un mundo más multilateral.

Conceptualmente, el ALBA es un diseño regional para apoyar procesos revolucionarios radicales dentro de los países miembros, con la finalidad de instituir un nuevo orden mundial. Expresa una voluntad de construir un mundo multipolar que asimismo contribuya al colapso de los Estados Unidos como una superpotencia global. "Chávez divide el campo político en aliados de Washington y adversarios de la potencia hegemónica" (Salazar, 2008, p. 226). En ese esquema, Venezuela sería el polo de poder alternativo, tal como reflejan las palabras del expresidente:

Tenemos que estar conscientes de lo siguiente: lo que pase en Venezuela influirá de muchas maneras en lo que siga ocurriendo en América Latina y en el mundo. De la Revolución bolivariana puede depender el destino de la humanidad (Chávez, 2011, p. 46).

Si bien la democracia liberal había servido en Venezuela para avalar la corrupción política y económica de los dos partidos tradicionales - COPEI y la Democracia Cristiana-, su régimen plebiscitario consintió los excesos de poder y la ilegalidad de decisiones institucionales. Incluso partidos menores como el Movimiento al Socialismo (MAS) y Causa R (Causa Radical) eran funcionales al régimen anterior de la IV República. El discurso del carismático presidente confrontaba y seducía estableciendo una clara distinción entre el pueblo y los traidores (Ellner, 2011). La imaginería de Simón Bolívar y

4 Los países miembros son: Antigua y Barbuda, Bolivia, Cuba, Dominica, Ecuador, Nicaragua, San Vicente y las Granadinas, y Venezuela. 
de una antigua estirpe de nacionalistas latinoamericanos del siglo XIX, ${ }^{5}$ que recuperaban las tradiciones indígenas y campesinas, e incluso raciales, a ojos de Chávez, redimía al pueblo degradado por las clases políticas burguesas y apátridas que habían arrasado a la nación. Sin embargo, como recuerda Ingrid Jiménez (2002, pp. 193-194), el "bolivarianismo representa una visión anacrónica de la sociedad internacional, que se opone a la globalización, pero que a la vez no ofrece alternativas diferentes a ella".

Mientras que la democracia como valor se incorporó a las sociedades latinoamericanas, Chávez solo reconocía un subtipo diseñado a su medida que diferenciaba entre democracia representativa y democracia participativa. El modelo venezolano apuntaba a una revolución que nunca se concretó: ${ }^{6}$

La suprema felicidad social es la visión de largo plazo que tiene como punto de partida la construcción de una estructura social incluyente, formando una nueva sociedad de incluidos, un nuevo modelo social, productivo, socialista, humanista, endógeno, donde todos vivamos en similares condiciones rumbo a lo que decía Simón Bolívar: "La Suprema Felicidad Social” (MPPP, 2007, p. 12).

Ese concepto de democracia participativa se exportaba a la región, ${ }^{7}$ utilizando una diplomacia paralela que tanto podía intervenir en la crisis ecuatoriana por la destitución del presidente Jamil Mahuad, como dar a apoyo financiero a candidatos cercanos a su visión del mundo, como Ollanta Humala en Perú o Cristina Kirchner en Argentina. Asimismo, se vinculaba sin mediaciones con movimientos y agrupaciones de izquierda y grupos ilegales escudados en una guerrilla setentista.

La pérdida de buena parte de sus aliados y el creciente malestar social condujeron en abril del 2002 a la detención de Chávez por un sector de las Fuerzas Armadas, tras los incidentes violentos con los que los chavistas habían respondido a una manifestación contra el régimen. El intento de imponer ilegítimamente a un presidente provisional - el empresario Pedro Carmona-, sumado al anuncio por este de la suspensión o disolución del entramado institucional, crearon una fuerte alarma entre los países vecinos,

5 De las figuras que Chávez reconocía como modelos, solo pertenecía al siglo XX el peruano José Carlos Mariátegui (14 de junio de 1894-16 de abril de 1930).

6 Las siete líneas estratégicas del Proyecto Nacional Simón Bolívar y la Venezuela socialista eran: i) la nueva ética socialista, ii) lograr la suprema felicidad social, iii) la democracia protagónica revolucionaria, iv) el modelo productivo socialista, v) la nueva geopolítica nacional, vi) la nueva geopolítica internacional, y vii) Venezuela como potencia energética mundial (Chávez, 2011: 25-27).

7 En la III Cumbre de las Américas, realizada en Quebec en el 2001, Chávez cuestionó la Carta Democrática Interamericana, que no incorporaba una cláusula para legitimar la democracia participativa. 
cuya presión contribuyó al fracaso de lo que era, a todas luces, un golpe de Estado. Repuesto en el poder, Chávez anunció su voluntad de dialogar para resolver la tensión que había llegado a dominar la vida del país. Pero sobre todo definió sus lineamientos a futuro: "De esta demostración sin precedentes en el mundo de cómo un pueblo y sus soldados detienen una contrarrevolución y hacen una contra-contrarrevolución” (Boscán Carrasquero, 2010, p. 70). Ello dio lugar a profundizar medidas paliativas para el pueblo: en el 2003 comienzan las "misiones", que inicialmente se pensaban como una ayuda temporaria, pero que quedaron como permanentes ya que eran un sustento en periodos eleccionarios. Esas misiones se extenderían a sus socios de ALBA. La exportación del socialismo repartiendo petróleo por medio de Petrocaribe, tractores modernos o créditos blandos, así como la creación del Sucre, la moneda regional del ALBA, o la Escuela de Defensa y Soberanía instalada en tierras de Bolivia, todos ellos fueron pasos para asegurar un predominio venezolano en el continente.

La movilización social, los programas de ayuda social y la denostación de los enemigos del pueblo respondían a un modelo caudillista que revindicaba constantemente lo popular para diferenciarse de las gestiones anteriores. Gracias a las ganancias del petróleo, pudo implementar una política nacional e internacional de subsidios que en el largo plazo se convirtieron en el cadalso de su proyecto.

Sin embargo, aún en los tiempos en que Chávez vivía, la redistribución del ingreso, el crecimiento económico y la disminución de la pobreza no fueron acordes a las promesas: "El discreto crecimiento de la economía [...] no revirtió los altos niveles de desocupación abierta que recibió el Gobierno, ni retrocedieron significativamente los índices de pobreza y pobreza extrema" (López Maya, 2008, p. 27).

Una de sus políticas que repercute en las relaciones regionales es la militarización de Venezuela, otorgando extensas funciones a las Fuerzas Armadas en la política nacional, provincial y local, al crear, tal como analizaba Alain Rouquié (1982), un partido militar. La politización de los militares (Trinkunas, 2009, pp. 99-100; Norden, 2014, p. 166) y una eventual guerra contra Colombia justificaban una desmedida compra de armamentos, desgastando el profesionalismo militar y creando alarma entre sus vecinos.

Las consecuencias de este modelo bolivariano tienen algunos aspectos positivos, como la alfabetización de amplios sectores de la sociedad o los servicios de salud de calidad cubiertos por médicos cubanos. Y tiene ade- 
más numerosas derivaciones negativas. Primero, el crecimiento abismal del crimen común y organizado. Segundo, el incremento de la violencia y la polarización que llevó a que hace un año murieran en enfrentamientos ciento veinticinco ciudadanos (El Tiempo, 2017). Tercero, una descomposición de la legalidad, visible en el 2012, en el proceso electivo que desplegó múltiples tácticas de intimidación a la población y que se continuó con el arresto de políticos opositores.

Hugo Chávez tuvo voluntad de cambio. Dijo: "Nuestra revolución es la primera del siglo XXI" (Chávez, 2011, p. 49). Recurrió al socialismo del siglo XXI, un híbrido poco consistente que con pinceladas del pasado y discursos ególatras y artificiosos llevó a la concentración de poder y el debilitamiento institucional. Además, nunca dejó de ser un elemento retórico y utópico, alejado de un programa de Gobierno, como bien describe Luz Barreto (2007, p. 64): "Ese proceso de transformación se ha estado haciendo en nombre del ideal utópico de un 'Socialismo del siglo XXI', una entidad inexistente y que, al pertenecer al siglo XXI, supuestamente estaría libre de todos los defectos que han sufrido todos los socialismos a lo largo de la historia". Ni el eje sobre la activa participación del Estado en la economía en detrimento del sector privado, ni la creación de un partido (PSUV) a imagen de la partidocracia tradicional, ni la creación de los consejos comunales controlados por el Gobierno, son puntales de una revolución del siglo XXI. Por el contrario, todas ellas son prácticas políticas añejas ineficientes en el pasado y que vuelven a naufragar en el presente.

\section{Comentarios finales}

Los modelos de esta marea rosa fueron paliativos, no revolucionarios. La vieja izquierda que ensoñaba con imitar la Revolución cubana de 1959 mutó en esta nueva izquierda que aún añora los "logros" de los Castro. Pero como bien señala Maristella Svampa (2017, pp. 60-61):

Desde el punto estrictamente político, asistimos a un populismo de alta intensidad, en el cual coexiste la crítica del neoliberalismo con el pacto con el gran capital; procesos de democratización con la subordinación de los actores sociales al líder; la apertura a nuevos derechos con la reducción del espacio del pluralismo y la tendencia a la cancelación de las diferencias, entre otros. 
El panorama de esa marea rosa incluía desde populistas autoritarios a demócratas sociales, que sucesivamente van dejando el poder sin gloria. ¿A que atribuir que el electorado opte por gobiernos de centro y centroderecha con enfoques pragmáticos y desideologizados? En otro escrito exponíamos que líderes surgidos de elecciones democráticas, en el ejercicio del mandato, concentraban en su propia persona la suma del poder, vaciando las instituciones, generando arbitrariedades y, en muchos casos, apropiándose corruptamente de recursos públicos (Diamint y Tedesco, 2015). No en todos los casos estos líderes dejaron tierra arrasada. Lenin Moreno, el actual presidente de Ecuador, hasta el momento de escribir este texto, anuncia combinar lo mejor del correísmo, modificando sus prácticas más autocráticas. El personalismo de Correa duró su Gobierno y no impidió el surgimiento de un líder con nuevas capacidades, algo que claramente no ocurrió en el caso de Venezuela. Tal vez una explicación es la que aporta Wilfredo Lozano (2005, p. 131) para entender por qué esta amalgama heterogénea no fecundó en un real cambio social:

Los llamados movimientos nacional-populares fueron los que más acercaron a los grupos de izquierda a una verdadera experiencia de movilización social de alcance de masas, y dicho movimiento nunca estuvo realmente liderado por partidos obreros, socialistas y mucho menos comunistas, sino por alianzas nacionales heterogéneas, en las cuales ocupaban un lugar central la clase media, sectores burocráticos estatales empeñados en la búsqueda de un espacio nacional propio, militares e incluso empresarios nacionalistas.

Las economías de estos países no auguraron tiempos mejores para los sectores excluidos, tal como demuestra Decio Machado (2012). En Venezuela, según fuentes oficiales, en julio del 2011, la banca privada había ganado ya un $81.7 \%$ más que en el mismo periodo del año anterior y, según datos del Instituto Nacional de Estadística (INE) de Venezuela, a pesar de las mejoras respecto al índice Gini en el país, tras más de una década de Gobierno "revolucionario", el $20 \%$ de los hogares con mayores ingresos económicos devenga en el $45.56 \%$ del ingreso total, mientras el $40 \%$ de los hogares más pobres apenas se apropia del $15.1 \%$ del ingreso. En Ecuador, el crecimiento acumulado del sector bancario privado fue durante los tres primeros años de Gobierno de Correa (20072009) un $70 \%$ superior al de los gobiernos neoliberales anteriores en el mismo periodo y, tras más de cinco años de Gobierno de la Revolución Ciudadana, sesenta y dos grupos económicos concentran el 41\% del PIB. En Bolivia, hasta 
noviembre del 2011, las recaudaciones fiscales lograban un récord histórico, atribuido a que al sector privado le iba muy bien.

La cooperación regional creció en calidad y cantidad. Se tendió a crear una identidad sudamericana. Sin embargo, en el tema militar hubo claras disparidades. Algunos países avanzaron en el control civil democrático de las Fuerzas Armadas; mientras otros no pudieron (o no quisieron) modificar la tradicional autonomía de las mismos; y otros empoderaron a los militares como actores políticos.

Mientras una tendencia democrática se alejaba de la visión Estado-céntrica para considerar la seguridad de los individuos — una seguridad societal donde el Estado no militariza las relaciones sociales y económicas-, los gobiernos de la izquierda securitizaron las relaciones regionales (Buzan, Wæver y De Wilde, 1997). Más inconcebible es aún la securitización de los recursos naturales, que llevó al exsecretario general de UNASUR, Alí Rodríguez Araque, a intimidar diciendo: "Todo recurso natural está alojado en la tierra, es decir el acceso del recurso natural convoca a un problema territorial, la defensa y la protección de la soberanía” (Radio Mundial, 2014).

Retomando la propuesta inicial, la marea rosa no fue roja ni democrática. Creó mecanismos para perpetuarse en el poder mientras ubicaba a los adversarios en el campo de enemigos. La política se tornó en un combate, y el Estado de derecho progresivamente perdió sus batallas. La reconfiguración regional apostó por un nuevo eje de poder sur-sur, tal vez influenciada por los escritos de Michael Klare (2001) y Simon Dalby $(2009,1998)$, detrás del cual se escondían tradicionales anhelos hegemónicos. La inserción internacional se edificó en contra de enemigos reales o figurados utilizando la misma retórica nacional de una lucha del pueblo contra las élites rapaces.

¿Ingenuidad? ¿Manipulación? O una desmedida ansia de poder personal que desarticuló revoluciones ciudadanas, bolivarianas, peronistas, laboristas, plurinacionales, mal concebidas y mucho peor ejecutadas. 


\section{Bibliografía}

Amorim, C. (2010). Brazilian foreign policy under president Lula (2003-2010): An overview. Revista Brasileira de Política Internacional, 53, pp. 214-240. Recuperado de: http://search.ebscohost.com.proxy.library.georgetown.edu/login.aspx?direct=true\&d $\mathrm{b}=\mathrm{aph} \& \mathrm{AN}=56487107 \&$ site $=$ ehost-live \&scope $=$ site .

Anderson, P. (2011). Lula's Brazil. London Reviews of Books, 33(7), pp. 3-12. Recuperado de: https://www.lrb.co.uk/v33/n07/perry-anderson/lulas-brazil.

Arditi, B. (2009). El giro a la izquierda en América Latina: ¿una política post-liberal? Ciências Sociais Unisino, 45(3), pp. 232-246.

Barreto, L. M. (2007). El socialismo del siglo XXI y los límites de las utopías en la racionalidad y la motivación humanas. Colombia Internacional, 66, pp. 52-69.

Boscán Carrasquero, G. E. (2010). Guillermo Ceresole y la revolución de Hugo Chávez: la relación caudillo, Ejército y pueblo. Revista de Ciencias Sociales, 25, pp. 57-73. Tarapacá, Universidad Arturo Prat.

Brainard, L. y Martínez-Díaz, L. (2009). Brazil as An Economic Superpower? Understanding Brazil's Changing Role in The Global Economy. Washington, D. C.: Brookings Institution Press.

Buzan, B., Wæver, O. y De Wilde, J. (1997). Security. A New Framework for Analysis. Londres: Lynne Rienner Publishers.

Cantamuttoi, F. J. (2013). ¿Giro a la izquierda? Nuevos gobiernos en América Latina. Relacso (marzo). Recuperado de: http://repositorio.flacsoandes.edu.ec/bitstream/10469/7290/1/RFLACSO-Re2-01-Cantamutto.pdf.

Carlsen, L. (2006). Latin America's Pink Tide? Foreign Policy in Focus, 15 de diciembre del 2006. Recuperado de: https://web.archive.org/web/20090910093646/http://www. fpif.org/fpiftxt/3806.

Castañeda, J. G. (2016). La muerte de la izquierda latinoamericana. The New York Times en Español (29 de marzo). Recuperado de: https://www.nytimes.com/es/2016/03/29/ la-muerte-de-la-izquierda-latinoamericana/.

Castañeda, J. G. (2006). Latin America's left turn. Foreign Affairs. Recuperado de: https:// www.foreignaffairs.com/articles/south-america/2006-05-01/latiname ricas-left-turn.

Castañeda, J. G. y Morales, M. A. (2008). Leftovers: Tales of the Latin American Left. Nueva York: Routledge.

Chávez, H. (2011). El socialismo del siglo XXI. Colección Cuadernos para el Debate. Caracas: Ministerio del Poder Popular para la Comunicación y la Información. 
Clarín (1999). Venezuela: echan a un argentino (4 de marzo). Recuperado de: https:// www.clarin.com/ediciones-anteriores/venezuela-echan-argentino_0_ry3UQCe0tg. html.

Dalby, S. (2009). Security and Environmental Change. Cambridge, Malden: Polity Press.

Dalby, S. (1998). Rethinking Geopolitics. Londres, Nueva York: Routledge.

Diamint, Rut y Tedesco, L. (2015). Latin America's Leaders. Londres: Zed Books.

Díaz, M. y Almeida, P. R. (2008). Brazil's Candidacy for Major Power Status. The Stanley Foundation, Working Paper. Recuperado de: http://www.academia.edu/5794444/077 Brazils_Candidacy_for_Major_Power_Status_with_Miguel_Diaz_2009_.

El Tiempo (2017). Los 125 rostros de los mártires de la represión venezolana (9 de agosto). Bogotá. Recuperado de: http:/www.eltiempo.com/justicia/investigacion/ quienes-son-las-125-personas-asesinadas-por-la-represion-en-venezuela-117864.

Ellner, S. (2011). Venezuela's social-based democratic model: innovations and limitations. Journal of Latin American Studies, 43(3), pp. 421-449.

Escobar, A. (2010). Latin America at a crossroads. Alternative modernizations, postliberalism, or post-development. Cultural Studies, 24 (1), pp. 1-65.

Gamboa Valenzuela, R. (2011). Chile y el liderazgo sudamericano de Brasil: ¿qué estrategia prefieren sus élites? Plataforma Democrática. Working Paper, 18. Recuperado de: https://mba.americaeconomia.com/sites/mba.americaeconomia.com/files/ricardogamboa_liderazgosudamericano.pdf.

Goldfrank, B. (2007). ¿De la ciudad a la nación? La democracia participativa y la izquierda latinoamericana. Nueva Sociedad, 212, pp. 53-66.

Gomes Saraiva, M. (2010). Brazilian foreign policy towards South America during the Lula administration: caught between South America and Mercosur. Revista Brasileira de Politica Internacional, 53, pp. 151-168.

Gomes Saraiva, M. y Valença, M. M. (2011). Brasil: potencia regional con intereses globales. América Latina en el sistema de gobernanza global. Diálogo Político, XXVIII(41), pp. 99-119.

González Urrutia, E. (2006). Las dos etapas de la política exterior de Chávez. Nueva Sociedad, 205, pp. 159-171.

Gratius, S. (2007). Brasil en las Américas. ¿Una potencia regional pacificadora? Documentos de trabajo FRIDE, 35. Madrid.

Homer Dixon, T. F. (2006). The Upside of Down: Catastrophe, Creativity, and the Renewal of Civilization. Toronto: Knopf.

Homer Dixon. T. F. (1999). Environment, Scarcity and Violence. Princeton: Princeton University Press. 
Hurrell, A. (2008). Lula's Brazil: a rising power, but going where? Current History, 107(706), pp. 51-57.

Jiménez, I. (2002). Venezuela y la OEA durante la era de Chávez. Politeia, 29, pp. 191-205.

Klare, M. (2008). La nueva geopolítica de la energía. The Nation (1 de mayo). Traducido por Sin Permiso. Recuperado de: http://www.sinpermiso.info/textos/ la-nueva-geopoltica-de-la-energa.

Klare, M. (2001). The new geography of conflict. Foreign Affairs, 80(3), pp. 49-61. Recuperado de: https://www.foreignaffairs.com/articles/russia-fsu/2001-05-01/ new-geography-conflict.

Levitsky, S. y Kenneth, M. R. (2011). The resurgence of the Latin American Left. Baltimore: John Hopkins University Press.

López Maya, M. (2008). Venezuela: ascenso y Gobierno de Hugo Chávez y sus fuerzas bolivarianas. Controversia, 190, pp. 11-53. Bogotá.

López Maya, M. (2007). ¿Del capitalismo rentista a cuál socialismo del siglo XXI? Aporrea (1 de abril). Recuperado de: https://www.aporrea.org/ideologia/a32697. html.

López Maya, M. y Lander, L. (2010). Venezuela 2009: en medio de dificultades avanza el modelo socialista del presidente Chávez. Revista de Ciencia Política, 30(2), pp. 537-553. Santiago de Chile.

López Segrera, F. (2016). América Latina: crisis del posneoliberalismo y ascenso de la nueva derecha. Buenos Aires: CLACSO. Recuperado de: http://biblioteca.clacso.edu.ar/gsdl/collect/clacso/index/assoc/D11890.dir/America-Latina-Crisis-delneoliberalismo.pdf.

Lozano, W. (2005). La izquierda latinoamericana en el poder. Interrogantes sobre un proceso en marcha. Nueva Sociedad, 197, 129-145.

Machado, D. (2012). Un socialismo del siglo XXI con más de 100 años de existencia. Viento Sur (3 de julio). Recuperado de: http://vientosur.info/spip.php?article6907.

Ministerio del Poder Popular de Planificación (2007). Líneas generales del plan de desarrollo económico y social de la nación 2007-2013. Caracas: MPPP. Recuperado de: http://www.mppp.gob.ve/wp-content/uploads/2013/09/Plan-de-laNaci\%C3\%B3n-2007-2013.pdf.

Muggah, R. (s/f). What is Brazil really doing in Africa? The Huffington Post. Recuperado de: $\quad$ https://www.huffingtonpost.com/robert-muggah/what-is-brazil-reallydoi_b_6413568.html. 
Neves, A. (2016). Politics and progress xenator Neves analyzes Brazil's role in the world. Harvard International Review, 28. Recuperado de: http://hir.harvard.edu/ article/? $\mathrm{a}=12674$.

Norden, D. (2014). The making of socialist soldiers: radical populism and civil-military relations in Venezuela, Ecuador and Bolivia. En D. Mares y R. Martínez (Eds.). Debating Civil-Military Relations in Latin America. Sussex: Sussex Academic Press.

Panizza, F. (2009). Nuevas izquierdas y democracia en América Latina. Revista CIDOB D'afers Internacionals, 85-86, pp. 78-88.

Paramio, L. (2003). Perspectivas de la izquierda en América Latina. Documento de Trabajo WP6/2003. Real Instituto Elcano. Recuperado de: http://biblioteca.ribei. org/379/1/PDF-006-2003-E.pdf.

Radio Mundial (2014). Alí Rodríguez Araque inauguró en Argentina conferencia "La defensa y los recursos naturales" (9 de junio). Recuperado de: http://www.radiomundial.com.ve/node/492.

Ramonet, I. (2014). Hugo Chávez. Mi primera vida: conversaciones con Hugo Chávez. Nueva York: Vintage Español.

Rohter, L. (2005). With new chief, Uruguay veers left, in a latin pattern. The New York Times (1 de marzo). Recuperado de: http://www.nytimes.com/2005/03/01/world/ americas/with-new-chief-uruguay-veers-left-in-a-latin-pattern.html.

Rouquié, A. (1982). L'État militaire en Amérique Latine. París: Éditions du Seuil.

Salazar, R. (2008). La política exterior de Hugo Chávez. Revista Mexicana de Política Exterior, 217(38), pp. 221254.

Schenoni, L. L. (2014). Brasil en América del Sur. La lógica de la unipolaridad regional. Nueva Sociedad, 250, pp. 138-149.

Sorj, B. y Fausto, S. (2011). El papel de Brasil en América del Sur: estrategias y percepciones mutuas. Buenos Aires: Catálogos.

Stolte, C. (2013). Brazil in Africa. Harvard International Review. Recuperado de: http:// hir.harvard.edu/article/?a=3078.

Svampa, M. (2017). Cuatro claves para leer América Latina. Nueva Sociedad, 268, pp. 50-64.

Thwaites, M. (2009). Después de la globalización neoliberal: ¿qué Estado en América Latina? Cuadernos del Pensamiento Crítico Latinoamericano, 32: http://biblioteca. clacso.edu.ar/clacso/se/20120509125518/cuadernos32.pdf.

Trinkunas, H. A. (2009). Las Fuerzas Armadas bolivarianas en los tiempos de Chávez ¿Desde el papel protagónico a la subordinación revolucionaria? En F. Agüero y C. Fuentes (Eds.). Influencias y resistencias. Militares y poder en América Latina. Santiago de Chile: Catalonia. 
Vilas, C. M. (2005). La izquierda latinoamericana y el surgimiento de regímenes nacional-populares. Nueva Sociedad, 197, pp. 84-99.

Weyland, K. (2009). The rise of Latin America's two lefts: insights from rentier state theory. Comparative Politics, 41, pp. 145-164.

Weyland, K. (2013). The threat from the populist left. Journal of Democracy, 24(3), pp. 18-32. 